ARTICLE

\title{
A fluoroxalate cathode material for potassium-ion batteries with ultra-long cyclability
}

Bifa Ji 12,5, Wenjiao Yao (1) 1,5, Yongping Zheng (1) 1,5, Pinit Kidkhunthod ${ }^{3}$, Xiaolong Zhou', Sarayut Tunmee ${ }^{3}$, Suchinda Sattayaporn ${ }^{3}$, Hui-Ming Cheng ${ }^{4 凶}$, Haiyan $\mathrm{He}^{1}$ \& Yongbing Tang (1) ${ }^{1,2 凶}$

Potassium-ion batteries are a compelling technology for large scale energy storage due to their low-cost and good rate performance. However, the development of potassium-ion batteries remains in its infancy, mainly hindered by the lack of suitable cathode materials. Here we show that a previously known frustrated magnet, $\mathrm{KFeC}_{2} \mathrm{O}_{4} \mathrm{~F}$, could serve as a stable cathode for potassium ion storage, delivering a discharge capacity of $\sim 112 \mathrm{mAh} \mathrm{g}^{-1}$ at $0.2 \mathrm{~A} \mathrm{~g}^{-1}$ and $94 \%$ capacity retention after 2000 cycles. The unprecedented cycling stability is attributed to the rigid framework and the presence of three channels that allow for minimized volume fluctuation when $\mathrm{Fe}^{2+} / \mathrm{Fe}^{3+}$ redox reaction occurs. Further, pairing this $\mathrm{KFeC}_{2} \mathrm{O}_{4} \mathrm{~F}$ cathode with a soft carbon anode yields a potassium-ion full cell with an energy density of $\sim 235 \mathrm{Wh} \mathrm{kg}^{-1}$, impressive rate performance and negligible capacity decay within 200 cycles. This work sheds light on the development of low-cost and high-performance K-based energy storage devices.

\footnotetext{
${ }^{1}$ Functional Thin Films Research Center, Shenzhen Institutes of Advanced Technology, Chinese Academy of Sciences, Shenzhen 518055, China. ${ }^{2}$ Shenzhen College of Advanced Technology, University of Chinese Academy of Sciences, Shenzhen 518055, China. ${ }^{3}$ Synchrotron Light Research Institute, 111 University Avenue, Muang District, Nakhon Ratchasima 30000, Thailand. ${ }^{4}$ Tsinghua-Berkeley Shenzhen Institute, Tsinghua University, Shenzhen 518055, China.

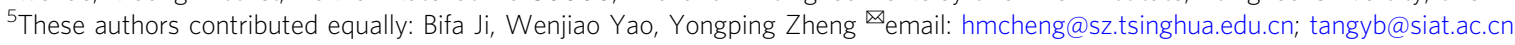


ithium-ion batteries (LIBs) are the state-of-the-art power technologies for portable electronic devices, electric vehicles, etc., owing to their high-energy density and long-term cycling life $\mathrm{e}^{1-6}$. However, the limited resource of lithium has restricted some applications of LIBs, especially in the field of large-scale energy storage for intermittent renewable energies, such as solar, wind, and tidal energy ${ }^{1,5}$. Recently, rechargeable energy storage devices based on other alkali elements, such as sodium-ion batteries $(\mathrm{SIBs})^{7-12}$ and potassium-ion batteries $(\mathrm{KIBs})^{13-16}$, have attracted extensive attention because of their obvious advantage in abundant resources. Between them, KIBs have higher working voltages because of the lower redox potential of $\mathrm{K} / \mathrm{K}^{+}\left(-2.93 \mathrm{~V} \text { for } \mathrm{K} / \mathrm{K}^{+} \text {, and }-2.71 \mathrm{~V} \text { for } \mathrm{Na} / \mathrm{Na}^{+} \text {vs SHE }\right)^{17}$. In addition, $\mathrm{K}$ ion electrolyte exhibits a relatively higher conductivity due to the weaker Lewis acidity of $\mathrm{K}$ and the resultant smaller radii of solvated $\mathrm{K}$ ions, and the corresponding system displays a lower interfacial resistance caused by the smaller desolvation energy ${ }^{18-20}$. Although KIBs can utilize graphite-related materials as the anode to achieve a capacity of $280 \mathrm{mAh} \mathrm{g}^{-1}$ via the formation of $\mathrm{KC}_{8}{ }^{21-24}$, the development of high-performance KIBs is so far limited by the lack of appropriate cathode materials.

As the size of $\mathrm{K}^{+}(1.38 \AA)$ is much larger than $\mathrm{Na}^{+}(1.02 \AA)$ and $\mathrm{Li}^{+}(0.76 \AA)^{25}$, large migration channels and stable crystal structures are essential for $\mathrm{K}$ ion migration, which raises a great challenge to develop suitable cathodes. Among the cathode materials reported for KIBs ${ }^{26-47}$, Prussian blue analogs (PBAs) have received most intensive studies with good capacity and favorable cycling stability because of their 3D open framework structures ${ }^{14,31-35,48-50}$. For instance, Goodenough et al. reported a cyanoperovskite $\mathrm{K}_{\mathrm{x}} \mathrm{MnFe}(\mathrm{CN})_{6}(0 \leq x \leq 2)$ cathode for KIBs, delivering a stable discharge capacity of $\sim 100 \mathrm{mAhg}^{-1}$ and a capacity retention of $91 \%$ over 100 cycles $^{33}$. More recently, Zhang et al. demonstrated RGO@PB@SSM cathode with a discharge capacity of $61.4 \mathrm{mAh} \mathrm{g}^{-1}$ and a lifespan of 305 cycles in $\mathrm{KIBs}^{31}$. Nevertheless, the preparation and handling of these materials are relatively difficult in controlling defects and water. The vacancies in the $\left[\mathrm{TM}(\mathrm{CN})_{6}\right](\mathrm{TM}=\mathrm{Fe}, \mathrm{Mn}$, etc. $)$ framework and residual water from the synthesis process reduce the available electron reservoir, and lead to slow kinetics, low Coulombic efficiency (CE), and poor cycle life ${ }^{24,28}$. Further optimization of PBAs or searching for new cathode materials with a similar 3D framework is promising strategies to break through the limitation of cathode and pave the way to practical use of KIBs.

Upon close inspection of a magnetic material, $\mathrm{KFeC}_{2} \mathrm{O}_{4} \mathrm{~F}$, we notice that its $3 \mathrm{D}$ open structure is similar to $\mathrm{PBAs} \mathrm{s}^{51,52}$, which is very promising for $\mathrm{K}$ ion storage. Therefore, we carry out systematical electrochemical investigation of $\mathrm{KFeC}_{2} \mathrm{O}_{4} \mathrm{~F}$ as a cathode material in KIBs using combined experimental and theoretical approaches. After optimization, a stable capacity of $112 \mathrm{mAh} \mathrm{g}^{-1}$ has been obtained and high-capacity retention of $94 \%$ is remained after 2000 cycles, with $0.003 \%$ capacity fading per cycle, which is the best long-term stability among the reported KIBs cathode materials. Moreover, a K-based full cell has been constructed by coupling this $\mathrm{KFeC}_{2} \mathrm{O}_{4} \mathrm{~F}$ cathode with a soft carbon anode, which exhibits a reversible capacity of $\sim 85 \mathrm{mAh} \mathrm{g}^{-1}$ (based on the mass of the cathode) and negligible capacity decay within 200 cycles, as well as impressive rate performance, paving the way for developing highly stable and low-cost K-based energy storage devices.

\section{Result}

Materials characterization. $\mathrm{KFeC}_{2} \mathrm{O}_{4} \mathrm{~F}$ crystallites were synthesized via an optimized hydrothermal process (see Methods). An optical image is shown in Fig. 1a, and the inset shows a single crystallite, which exhibits a typical tetra-prismatic morphology in the size of $\sim 1.0 \times 0.6 \times 0.5 \mathrm{~mm}$. The phase of the prepared sample was checked by Rietveld refinement on powder X-ray diffraction (XRD) as illustrated in Fig. 1b. All diffraction peaks could be well indexed in the space group of $C m c 2_{1}$ with the lattice parameters $a=7.7611(5) \AA, b=11.8591(1) \AA, c=10.4037(7) \AA$, in accordance with the previously reported data ${ }^{52}$. The Rietveld refinement also revealed that there is no detectable impurity in the sample. A sheet of $\mathrm{KFeC}_{2} \mathrm{O}_{4} \mathrm{~F}$ (Supplementary Fig. 1) with the size of $\sim 6 \mu \mathrm{m} \times 4 \mu \mathrm{m} \times 80 \mathrm{~nm}$ was prepared by focused ion beam and then examined by a transmission electron microscope (TEM) and energy dispersion spectroscopy (EDS), as shown in Fig. 1c. The results confirm the evenly distribution of $\mathrm{K}, \mathrm{Fe}, \mathrm{C}, \mathrm{O}$, and $\mathrm{F}$ in the obtained crystallites. The Fourier transform infrared and Raman spectra shown in Supplementary Fig. 2 confirm the existence of typical vibration peaks of the oxalate group (Supplementary Table 1$)^{53}$. Meanwhile, our attempts in taking highresolution TEM or selected area electron diffraction proved unsatisfactory owing to the sample's sensitivity to intense electron beams, similar to some other oxalate, fluorosulphates and metalorganic frameworks. ${ }^{54-57}$

The thermal behavior of $\mathrm{KFeC}_{2} \mathrm{O}_{4} \mathrm{~F}$ was analyzed by simultaneous thermogravimetric-differential scanning calorimetry and variable-temperature XRD. As shown in Fig. 1d, negligible weight loss was detected from the TG curve until $310^{\circ} \mathrm{C}$, confirming the good stability of $\mathrm{KFeC}_{2} \mathrm{O}_{4} \mathrm{~F}$ below this temperature. A distinct weight loss step of $\mathrm{ca} .32 \%$ from $310^{\circ} \mathrm{C}$ to $450^{\circ} \mathrm{C}$ was exhibited in the TG curve, accompanied by a broad endothermic peak in the DSC curve, which is mainly attributed to the decomposition of oxalate groups. Thereafter, XRD patterns at different temperatures were measured between room temperature and $310^{\circ} \mathrm{C}$ (Fig. 1e), demonstrating the excellent phase stability in the chosen temperature range.

Electrochemical performance as KIB cathode in half cells. To apply $\mathrm{KFeC}_{2} \mathrm{O}_{4} \mathrm{~F}$ as a cathode material in $\mathrm{KIBs}$, pristine $\mathrm{KFe}$ $\mathrm{C}_{2} \mathrm{O}_{4} \mathrm{~F}$ was downsized and mixed with a carbon conductor by ball milling to improve its electric conductivity. The purity and morphology of samples after each treatment were checked by XRD, scanning electron microscope (SEM) and EDS element mapping of K, Fe, C, O, F (details in Supplementary Figs. 3, 4). After these treatments, the diffraction peaks of XRD patterns are consistent with those of the pristine sample, which indicates no phase change during ball milling. From SEM images, $\mathrm{KFeC}_{2} \mathrm{O}_{4} \mathrm{~F}$ particles with an average size of $\phi \sim 250 \mathrm{~nm}$ were homogeneously mixed with the conductive carbon after ball milling, significantly smaller than hand-ground $\mathrm{KFeC}_{2} \mathrm{O}_{4} \mathrm{~F}$ particles (Supplementary Fig. 5). This composite cathode was installed in coin-type cells to characterize the electrochemical performance of $\mathrm{KFeC}_{2} \mathrm{O}_{4} \mathrm{~F}$.

$\mathrm{K}$ half-cells were firstly fabricated in Ar-filled glove box, with $\mathrm{K}$ metal as anode and $1 \mathrm{M} \mathrm{KPF}$ in $\mathrm{PC}+\mathrm{EC}(1: 1 \mathrm{v} / \mathrm{v})$ as the electrolyte. Typical cyclic voltammogram (CV) curves of the $\mathrm{KFeC}_{2} \mathrm{O}_{4} \mathrm{~F}$ electrode in 10th, 20th, and 30th cycles in the range of 1.5-4.6 $\mathrm{V}$ were recorded at a scan rate of $0.1 \mathrm{mV} \mathrm{s}^{-1}$ (Fig. 2a). The overlapping of these curves indicated the good cyclic stability of the cathode. Meanwhile, a pair of peaks at $3.80 / 3.35 \mathrm{~V}$ is observed in the electrochemical processes during the de-intercalation/intercalation of $\mathrm{K}$ ions, corresponding to $\mathrm{Fe}^{2+} / \mathrm{Fe}^{3+}$ redox reactions. The rate performance of the cathode is plotted in Fig. 2b, c. Similar profiles of charge-discharge curves are observed, with moderate increase of discharge plateau from 0.5 to $0.1 \mathrm{Ag}^{-1}$ (Fig. 2b). In addition, the discharge capacity of $\mathrm{KFeC}_{2} \mathrm{O}_{4} \mathrm{~F}$ cathode is 126,102 , 93, 89, and $87 \mathrm{mAhg}^{-1}$ for $0.1,0.2,0.3,0.4$, and $0.5 \mathrm{Ag}^{-1}$, respectively, with the corresponding CEs over 95\% (Fig. 2c). The discharge capacity is recovered to $126 \mathrm{mAh} \mathrm{g}^{-1}$ when the current density is changed back to $0.1 \mathrm{~A} \mathrm{~g}^{-1}$, demonstrating both good rate capability and good capacity retention of $\mathrm{KFeC}_{2} \mathrm{O}_{4} \mathrm{~F}$. Moreover, a 
a

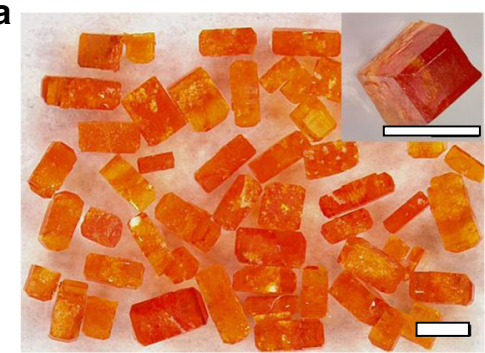

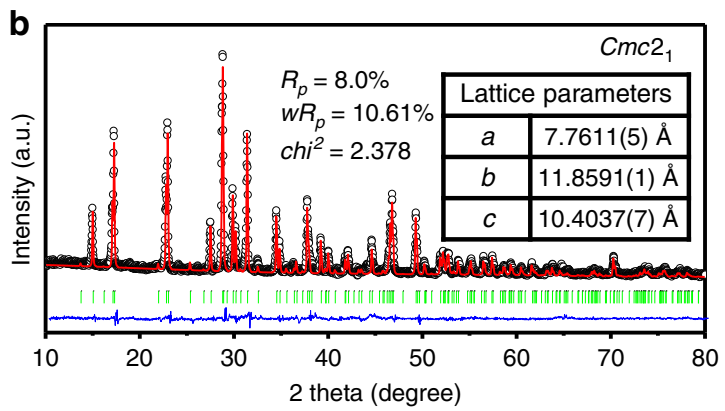
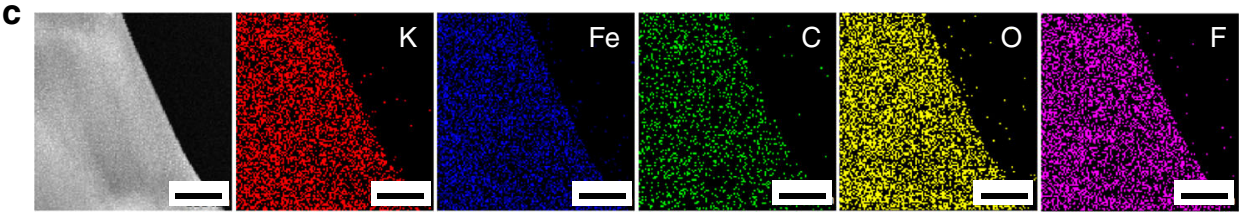

d
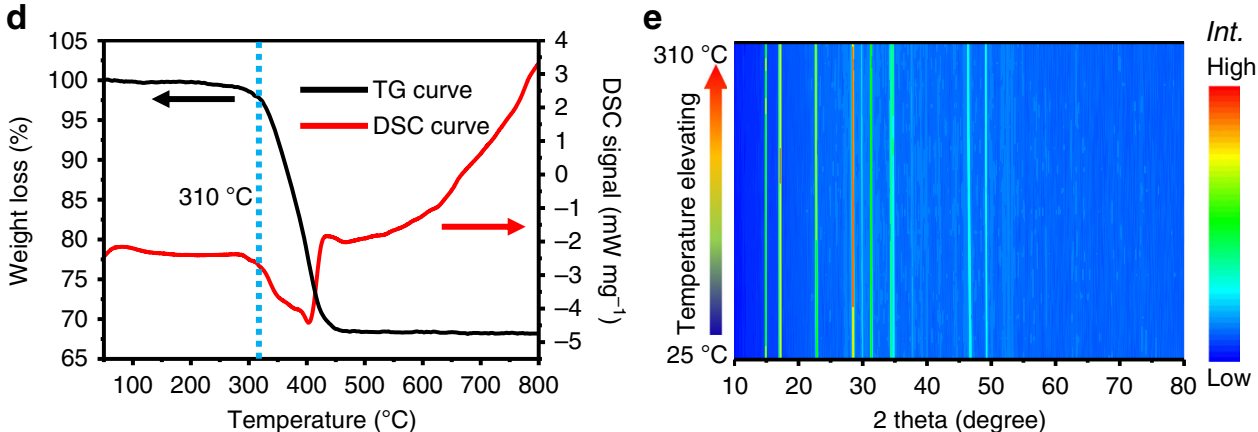

Fig. 1 Characterization of $\mathbf{K F e C}_{\mathbf{2}} \mathbf{O}_{\mathbf{4}} \mathbf{F}$. a Optical images of as-synthesized crystallites. The inset shows a tetra-prismatic single crystal in the size of $\sim 1.0 \times$ $0.6 \times 0.5 \mathrm{~mm}$. (scale bar $=1 \mathrm{~mm})$ b Rietveld fitness of powder XRD $\left(C u K_{\alpha}\right)$ on a pristine sample. The inset shows the result of the fitness. $\mathbf{c}$ TEM and corresponding EDS mapping of $\mathrm{K}, \mathrm{Fe}, \mathrm{C}, \mathrm{O}, \mathrm{F}$. (scale bar $=500 \mathrm{~nm}$ ) d TG and DSC curves of a powder sample. e Variable-temperature XRD from $25^{\circ} \mathrm{C}$ to $310^{\circ} \mathrm{C}$ in air gas flow $\left(\mathrm{Cu} K_{\alpha}\right)$.

half cell was measured by the galvanostatic intermittent titration technique (details in Supplementary Fig. 6), to reveal $\mathrm{K}$ ion diffusion kinetics indicated by chemical diffusion coefficients $(D)$. The results show a variation of $D$ values with depths of charge/ discharge as shown in Supplementary Fig. 7. On the whole, the $D$ values of $10^{-10}-10^{-12} \mathrm{~cm}^{2} \mathrm{~s}^{-1}$ were at the similar level to that of $\mathrm{Li}^{+}$in popular cathode materials $\left(D\right.$ of $\mathrm{Li}^{+}$in $\mathrm{LiFePO}_{4}\left(10^{-14}\right.$ $\left.-10^{-15} \mathrm{~cm}^{2} \mathrm{~s}^{-1}\right)$ and in $\left.\mathrm{LiMn}_{2} \mathrm{O}_{4}\left(10^{-11}-10^{-9} \mathrm{~cm}^{2} \mathrm{~s}^{-1}\right)\right)^{58}$. Thus, the good rate performance of $\mathrm{KFeC}_{2} \mathrm{O}_{4} \mathrm{~F}$ was likely attributed to the fast $\mathrm{K}$ ion diffusion in the $\left[\mathrm{FeC}_{2} \mathrm{O}_{4} \mathrm{~F}\right]$ framework.

The cycling performance of the $\mathrm{KFeC}_{2} \mathrm{O}_{4} \mathrm{~F}$ cathode was illustrated in Fig. 2d. The battery with a $\mathrm{KFeC}_{2} \mathrm{O}_{4} \mathrm{~F}$ cathode delivered a stable discharge capacity of $\sim 112 \mathrm{mAh} \mathrm{g}^{-1}$ at $0.2 \mathrm{Ag}^{-1}$ after electrochemical activation in initial several cycles and kept a high capacity retention of $94 \%$ after 2000 cycles, with only $0.003 \%$ capacity fading per cycle. Noted that the voltage profiles of the first few cycles differ from the stabilized ones, possibly attributing to the reaction of conductive carbon wrapped on active material. To figure out the main underneath mechanism, we checked the voltage profile of the conductive carbon, and found out that the first charge-discharge profile of $\mathrm{KFeC}_{2} \mathrm{O}_{4} \mathrm{~F}$ composite cathode (Supplementary Fig. 8a) resembles that of the conductive carbon (Supplementary Fig. 8c). As the active $\mathrm{KFeC}_{2} \mathrm{O}_{4} \mathrm{~F}$ cathode had been mixed thoroughly with conductive carbon by ball milling, our $\mathrm{KFeC}_{2} \mathrm{O}_{4} \mathrm{~F}$ particles had been wrapped entirely by the conductive carbon, so that the first charge-discharge process was mainly originated from the reaction of conductive carbon. As the process went on, $\mathrm{KFeC}_{2} \mathrm{O}_{4} \mathrm{~F}$ particles became more and more exposed to the electrolyte, and the intrinsic electrochemical feature of $\mathrm{KFeC}_{2} \mathrm{O}_{4} \mathrm{~F}$ became more and more dominating in following charge-discharge profiles. Although the cell based on the conductive carbon initially delivered a relatively high capacity, but its capacity faded gradually to $\sim 30 \mathrm{mAh} \mathrm{g}^{-1}$ after 1000 cycles (Supplementary Fig. 8d). Considering the content of the carbon black in $\mathrm{KFeC}_{2} \mathrm{O}_{4} \mathrm{~F}$ cathode material is $25 \%$, its contribution to the whole capacity shall be $\sim 7 \mathrm{mAh}^{-1}$, thus the obtained capacity on composite cathode material mainly comes from the $\mathrm{KFeC}_{2} \mathrm{O}_{4} \mathrm{~F}$ compound. Stable discharge capacities of $\sim 126 \mathrm{mAh} \mathrm{g}^{-1}$ and $80 \mathrm{mAhg}^{-1}$ were obtained at $0.1 \mathrm{Ag}^{-1}$ and $0.5 \mathrm{Ag}^{-1}$, respectively, (Supplementary Fig. 9), with CE constantly above 96.5\%. The galvanostatic charging-discharging (GCD) curves at the 1000th and 2000th cycles at $0.2 \mathrm{Ag}^{-1}$ match well with that of the 100th cycle (Fig. 2e). A stable medium discharging voltage $\left(V_{m}\right)$ of $\sim 2.85 \mathrm{~V}$ of the cell is observed for 2000 cycles (Fig. 2f). These results demonstrate the outstanding cyclic stability of the cell throughout the testing period (around $2000 \mathrm{~h}$ ). Further, to reveal the distinctive nature of the long-term reaction kinetics of $\mathrm{KFeC}_{2} \mathrm{O}_{4} \mathrm{~F}$ cathode, electrochemical impedance spectroscopy (EIS) tests in different cycles were performed, with the Nyquist plots shown in Supplementary Fig. 10. Each plot comprises a depressed semicircle in the high-medium frequency region originated from the charge transfer resistance $\left(R_{c t}\right)$, and a sloping line in the low frequency region attributed to Warburg impedance. It is obviously seen that the $R_{c t}$ value rises first and descends later in the first five cycles, probably owing to the generation of cathode electrolyte interphase films. The $R_{c t}$ kept almost constant after the first 10 cycles, again revealing the good stability of the cell. Dozens of compounds have been thoroughly investigated so far as cathode materials for KIBs. Figure $2 \mathrm{~g}$ shows the comparison of cycling stability between $\mathrm{KFeC}_{2} \mathrm{O}_{4} \mathrm{~F}$ and the reported cathode materials for KIBs (detailed data refer to Supplementary Table 2), demonstrating that the cycling 

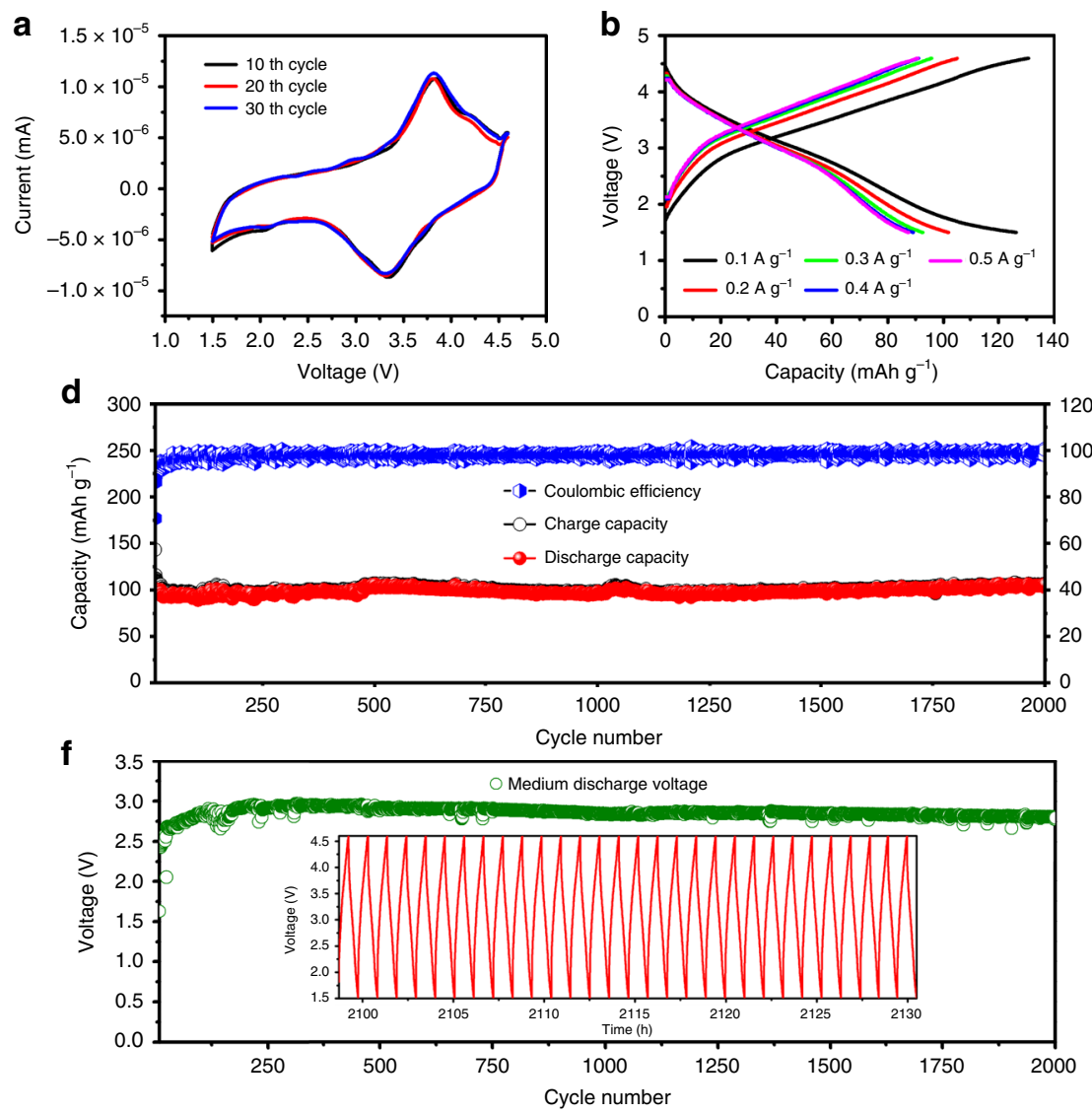
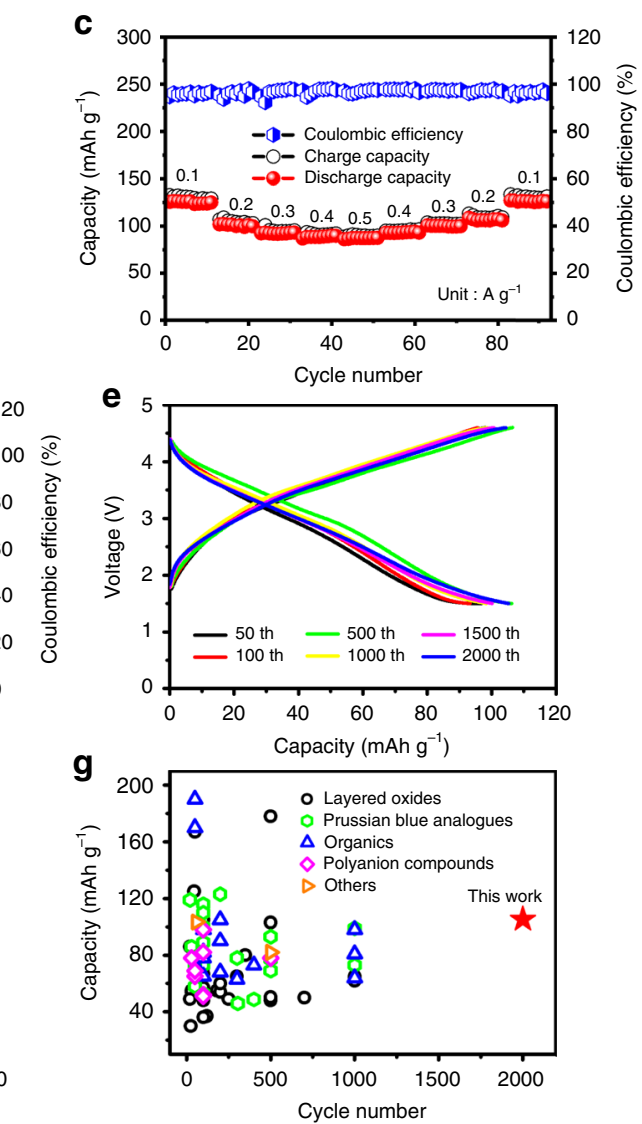

Fig. 2 Electrochemical measurements of $\mathbf{K F e C}_{\mathbf{2}} \mathbf{O}_{\mathbf{4}} \mathbf{F}$ in $\mathbf{K}$ half-cells. a CV curves in different cycles at a scan rate of $0.1 \mathrm{mV} \mathrm{s}{ }^{-1}$. b Galvanostatic charge-discharge curves at different current densities of $0.1-0.5 \mathrm{~A} \mathrm{~g}^{-1}$. c Rate performance under different current densities. $\mathbf{d}$ Cycling performance at $0.2 \mathrm{~A} \mathrm{~g}^{-1}$ for 2000 cycles, and $\mathbf{e}$ the corresponding charge-discharge curves of diverse cycles, and $\mathbf{f}$ medium discharge voltages. Inset of $\mathbf{f}$ is the charge-discharge curves for the final 30 cycles. $\mathbf{g}$ The comparison of cycling stability between our work and recently reported cathode materials (detailed in Supplementary Table 2) for potassium-ion batteries.

stability of this cathode is significantly better than that of reported KIB cathodes.

Investigation of the reaction mechanism. To investigate the redox chemistry of $\mathrm{KFeC}_{2} \mathrm{O}_{4} \mathrm{~F}$ as a cathode in KIBs, synchrotronbased in situ X-ray absorption spectra (in situ XAS) have been measured on a half cell during charging-discharging process, which is known as an advanced method to study the oxidation states and coordination environments of transition metals. The $\mathrm{Fe}$ absorption edge from 7000 to $7400 \mathrm{eV}$ was recorded in a gas ionization chamber to track the incident and transmitted X-ray intensities in the transmission mode, whereas the GCD curve of the cell was recorded simultaneously in a battery testing system (see Methods). As a comparison, $\mathrm{FeO}$ and $\mathrm{Fe}_{2} \mathrm{O}_{3}$ were used for references. Figure 3a shows a typical GCD curve of the in situ cell during XAS measurement, and the color highlighted dots represent the states where in situ XAS were recorded. Figure 3b, c display the $\mathrm{Fe} K$-edge $\mathrm{X}$-ray absorption near-edge spectra (XANES) during charging and discharging, respectively, and Fig. 3d, e illustrate the corresponding extended synchrotron X-ray absorption fine-structure (EXAFS) spectra after $k^{2}$-weighted Fourier transform. The Fe $K$-edge XANES spectra shown in Fig. $3 \mathrm{~b}$ shifted to higher energy region during charging, which is ascribed to the transformation of $\mathrm{Fe}^{2+}$ to $\mathrm{Fe}^{3+}$ during $\mathrm{K}$ ion extraction. An opposite shift was observed during discharging (Fig. 3c), attributing to the reduction of $\mathrm{Fe}^{3+}$ to $\mathrm{Fe}^{2+}$ during $\mathrm{K}$ ion insertion. The change of XANES in a full cycle indicates a reversible change of Fe valence upon $\mathrm{K}$ ion extraction/insertion. In addition, the outline of spectra was mostly identical throughout a full cycle, indicating the high stability of the octahedral $\left[\mathrm{FeO}_{4} \mathrm{~F}_{2}\right]$ motif. In the analysis of EXAFS, oscillations within $k=2.6-10 \AA^{-1}$ were chosen to minimize noise. As illustrated in Fig. $3 d$, e, broad peaks were identified at $\sim 1.5 \AA$, corresponding to fourfold $\mathrm{Fe}-\mathrm{O}$ and twofold $\mathrm{Fe}-\mathrm{F}$ bonds in the octahedral $\left[\mathrm{FeO}_{4} \mathrm{~F}_{2}\right]$ motif. The peak shifted to lower distance upon charging, and vice versa upon discharging, suggesting $\mathrm{Fe}-\mathrm{O} /$ $\mathrm{F}$ bonds contraction/expansion. The overlaps of XANES and EXAFS curves of the cathode at the beginning of the charging and the end of discharging (Supplementary Figs. 11, 12) also indicate the good reversibility of the process.

Apart from in situ synchrotron XAS, ex situ XRD patterns were also collected to explore the structural stability and the change of the lattice during $\mathrm{K}$ ion extraction/insertion. Figure $3 \mathrm{f}$ shows the $\mathrm{XRD}$ spectra of $\mathrm{KFeC}_{2} \mathrm{O}_{4} \mathrm{~F}$ under different charging/discharging states. A broad peak centered at $20.5^{\circ}$ was originated from the conductive carbon black (Supplementary Fig. 13a). It can be seen that the profiles of XRD patterns were almost unchanged within the cycle, indicating the good structural stability of the framework upon $\mathrm{K}$ ion extraction and insertion. The characteristic peaks of ex situ XRD in $22.5-23.3^{\circ}$ and $28.3-29.2^{\circ}$ are highlighted in Fig. 3g, h, corresponding to (200) and (221) plane, respectively. Both characteristic peaks display the same tendency of changes, that is, shifting to higher angle during charging and vice versa during discharging, corresponding to the lattice contraction and 


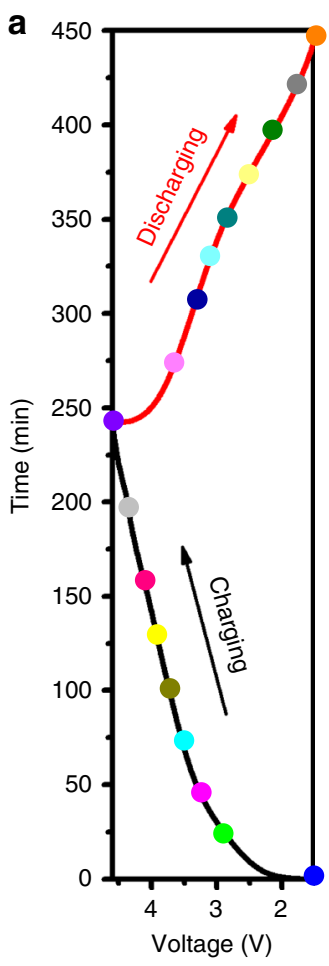

f

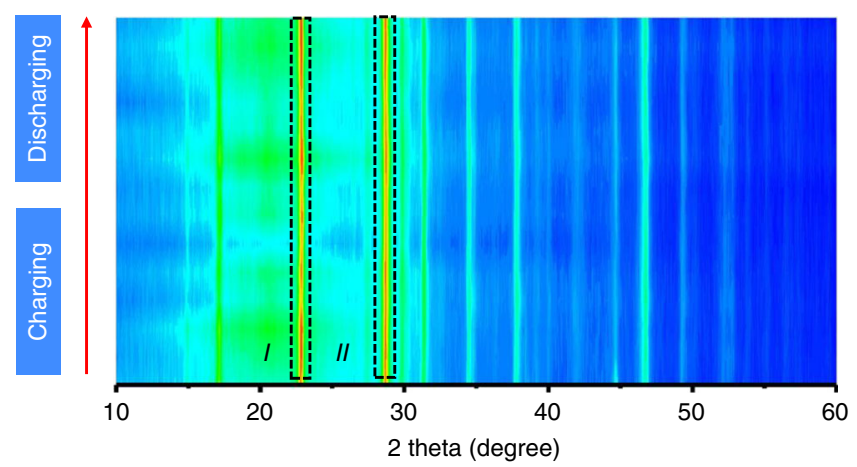

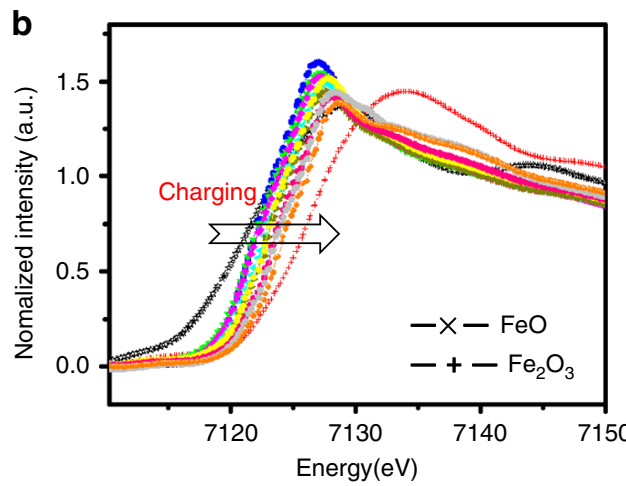
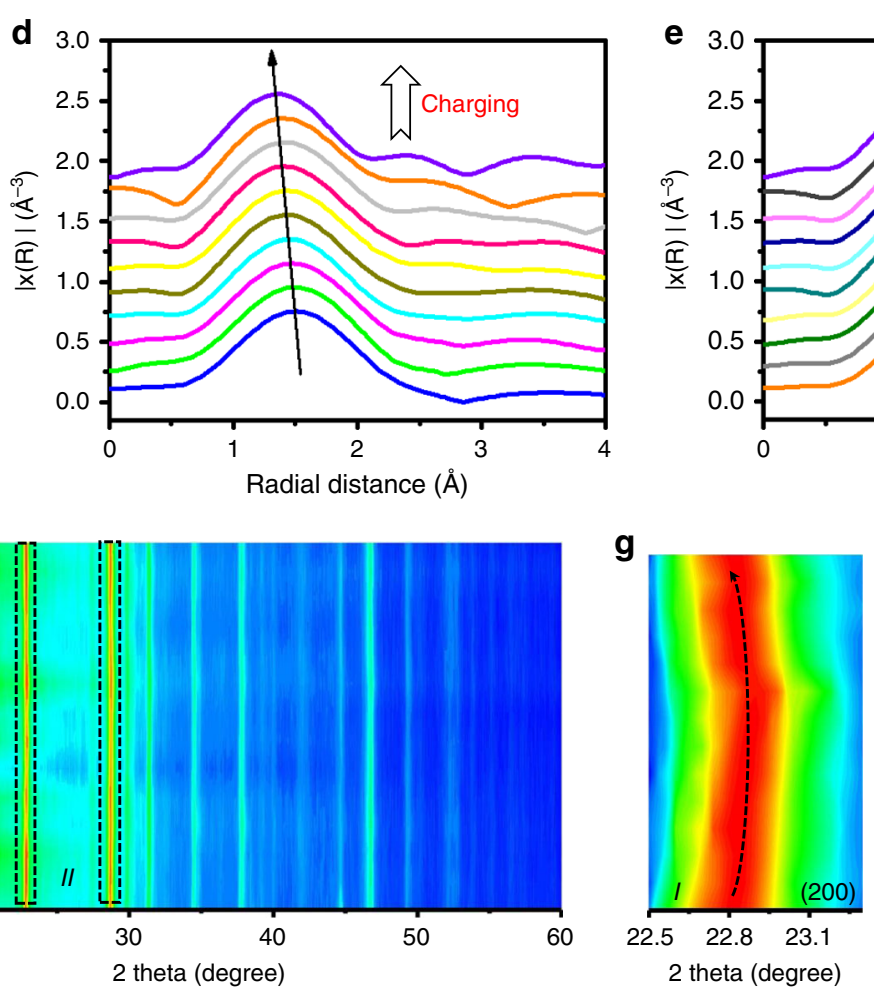
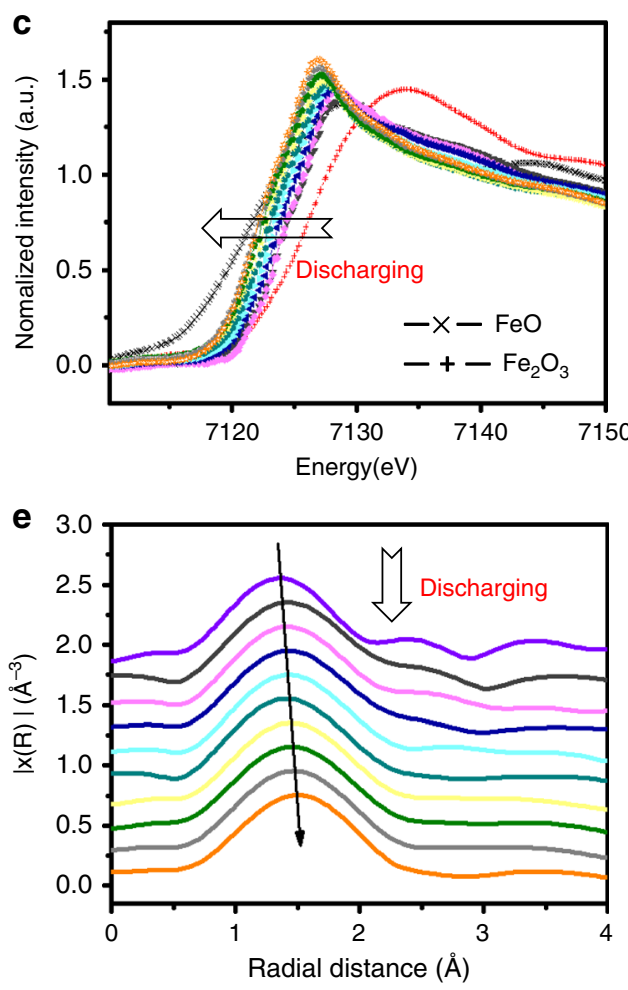

h

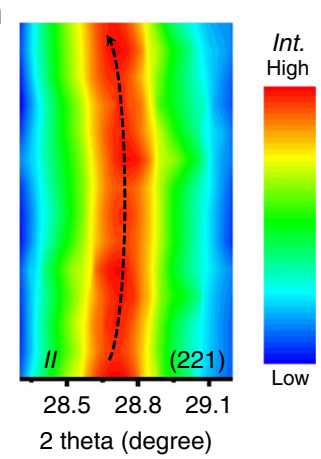

Fig. 3 The structural evolution and charge compensation mechanism of the $\mathbf{K F e C}_{\mathbf{2}} \mathbf{O}_{\mathbf{4}} \mathbf{F}$ cathode. a A typical galvanometric charging-discharging curve of a stabilized half cell in the window of $1.5-4.6 \mathrm{~V}$ at a current density of $0.1 \mathrm{~A} \mathrm{~g}^{-1}$ and corresponding synchrotron Fe $K$-edge XANES during charging $\mathbf{b}$ and discharging $\mathbf{c}$, and Fe EXAFS during charging $\mathbf{d}$ and discharging $\mathbf{e}$. $\mathbf{f}$ Ex situ XRD of $\mathrm{KFeC}_{2} \mathrm{O}_{4} \mathrm{~F}$ upon $\mathrm{K}$ ions extraction and reinsertion and the highlighted characteristic peaks in $22.5-23.3^{\circ}$ corresponding to (200) plane $\mathbf{g}$ and $28.3-29.2^{\circ}$ corresponding to (221) plane $\mathbf{h}$.

expansion, respectively. It should be noted that the shift is very small and reversible, indicating the finite volumetric change and high reversibility during the extraction/insertion of $\mathrm{K}$ ions. Moreover, a XRD pattern of $\mathrm{KFeC}_{2} \mathrm{O}_{4} \mathrm{~F}$ cathode after long cycling was collected, indicating the well-maintained crystal structure after long cycling (Supplementary Fig. 13b).

First-principle calculations. To illustrate the fundamental mechanism of the stable while reversible potassium storage in the framework of $\mathrm{KFeC}_{2} \mathrm{O}_{4} \mathrm{~F}$, in-depth structural analysis was performed, along with density functional theory (DFT) calculations based on the DFT $+U$ method, in which the Hubbard $U$ term stands for the strong onsite Coulomb repulsion of localized Fe $3 d$ electrons. As illustrated in Fig. $4 \mathrm{a}, \mathrm{KFeC}_{2} \mathrm{O}_{4} \mathrm{~F}$ has a $2 \mathrm{D}$ $\left[\mathrm{Fe}\left(\mathrm{C}_{2} \mathrm{O}_{4}\right)\right]_{\infty}$ network with $\mathrm{F}$ ions linking adjacent layers common, building a three dimensional $\left[\mathrm{Fe}\left(\mathrm{C}_{2} \mathrm{O}_{4}\right) \mathrm{F}\right]_{\infty}$ skeleton. Three tunnels along the [100], [010], and [001] directions can be delimited with the cross-section dimensions of $(4.3 \times 4.2 \AA),(6.3 \times 3.7 \AA)$, and $(6.3 \times 3.3 \AA)$, respectively. Such large tunnels are feasible for
$\mathrm{K}$ ion migration. The DFT calculations results that the lattice parameters of $\mathrm{KFeC}_{2} \mathrm{O}_{4} \mathrm{~F}$ transform from $a=7.793 \AA$, $b=$ $11.911 \AA, c=10.463 \AA$, to $a=7.721 \AA, b=11.539 \AA, c=10.098$ $\AA$, after full extraction of $\mathrm{K}$ from $\mathrm{KFeC}_{2} \mathrm{O}_{4} \mathrm{~F}$ to form $\mathrm{FeC}_{2} \mathrm{O}_{4} \mathrm{~F}$ (Fig. 4b). This lattice change only results in $7.6 \%$ volume shrinkage, comparable to that of $\mathrm{LiFePO}_{4}(\sim 7.8 \%)^{59}$. Moreover, the smooth evolution of lattice constants and volume change at varied charging stages (Fig. 4c) could reduce the possibility of mechanical failure (e.g., crack formation) during cycling.

Figure $5 \mathrm{a}$ presents the detailed structural evolution of $\mathrm{KFeC}_{2} \mathrm{O}_{4} \mathrm{~F}$ at different charging stages based on DFT calculation, which reveals that the $3 \mathrm{D}$ framework undergoes a slight change with the marginal shrinking of octahedral $\left[\mathrm{FeO}_{4} \mathrm{~F}_{2}\right]$ building blocks during charge. More specifically, the Fe-O bonds on the $b c$ plane shorten by $\sim 0.16 \AA$ upon full depotassiation, whereas the Fe-F bonds along the $a$ axis undergo much less shrinkage by $0.06 \AA$, showing that the interlayer bridging $\mathrm{F}$ ions play a pivotal role in stabilizing the $3 \mathrm{D}$ framework. Along with the structural changes, Fig. $5 \mathrm{~b}$ displays the corresponding density of states of the Fe $3 d$ orbitals. In the pristine $\mathrm{KFeC}_{2} \mathrm{O}_{4} \mathrm{~F}, \mathrm{Fe}^{2+}$ exhibits a 
a
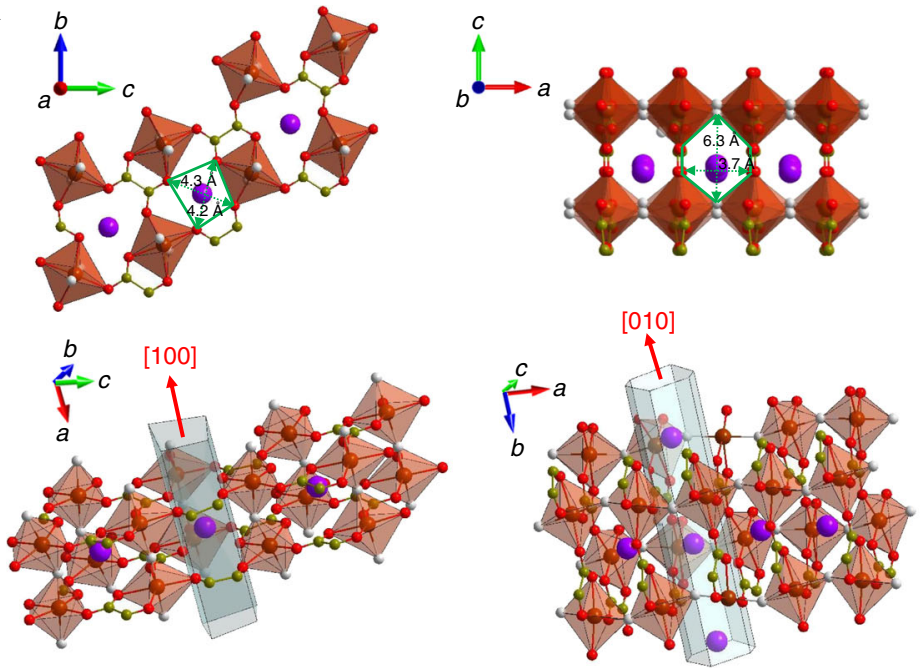

b
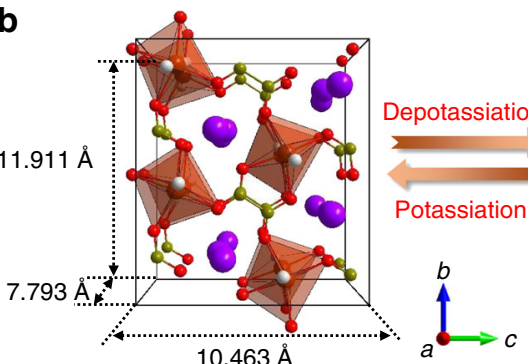
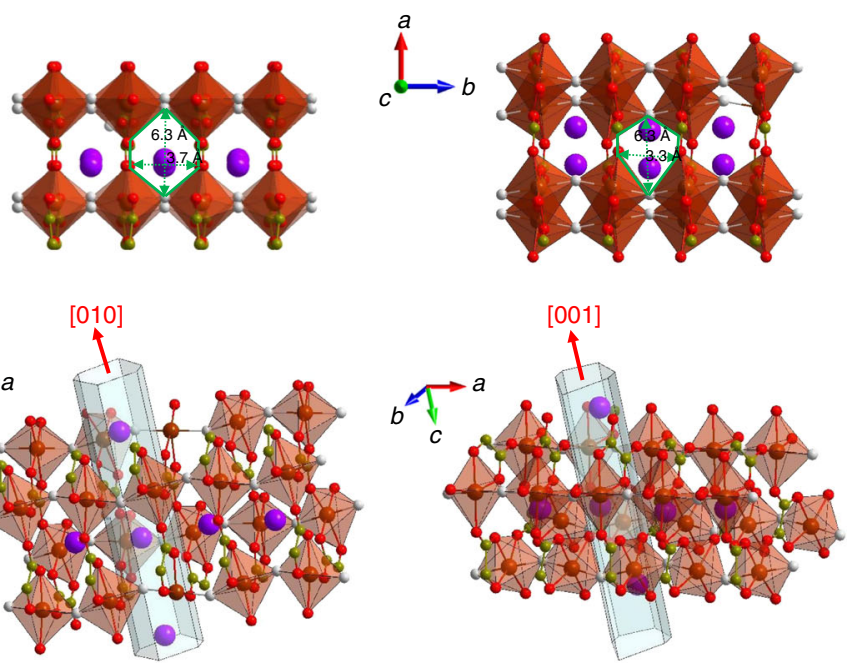

C

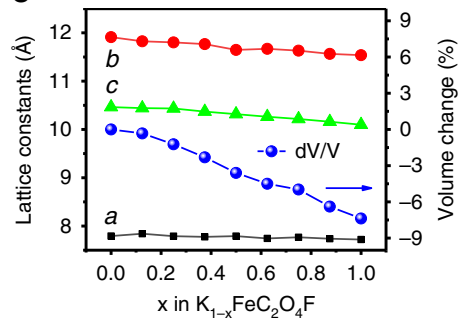

Fig. 4 The structure of the $\mathbf{K F e C}_{\mathbf{2}} \mathbf{O}_{\mathbf{4}} \mathbf{F}$ cathode. a Projections of the $\mathrm{KFeC}_{2} \mathrm{O}_{4} \mathrm{~F}$ structure along the [100], [010], and [001] directions and corresponding tunnels for possible ion migrations, with tunnel size highlighted. $\left[\mathrm{FeO}_{4} \mathrm{~F}_{2}\right]$ octahedra are represented in brown. $\mathbf{b}$ Unit cell of $\mathrm{KFeC}_{2} \mathrm{O}_{4} \mathrm{~F}$ in potassiation/ depotassiation states based on DFT calculation. $\mathbf{c}$ The lattice parameters and volume change of $\mathrm{K}_{1-x} \mathrm{FeC}_{2} \mathrm{O}_{4} \mathrm{~F}$ as a function of the charge state $x$.

high-spin electron configuration $t_{2 \mathrm{~g}}{ }^{4} e_{\mathrm{g}}{ }^{2}(S=2)$. It is inferred that the spin-down states $\left(t_{2 \mathrm{~g}}\right)$ shall be redox active since they locate right below the Fermi level $\left(E_{\mathrm{F}}\right)$. As potassium ions being extracted, these $t_{2 \mathrm{~g}}$ states of $\mathrm{Fe}^{2+}$ shift gradually above the $E_{\mathrm{F}}$ while emigrating electrons to surrounding anions. In contrast, its majority spin-up states shift further below the $E_{\mathrm{F}}$. In the fullcharging $\left[\mathrm{FeC}_{2} \mathrm{O}_{4} \mathrm{~F}\right], \mathrm{Fe}^{3+}$ exhibits a half-filled electron configuration $t_{2 \mathrm{~g}}{ }^{3} \mathrm{e}_{\mathrm{g}}{ }^{2}$ in the highest spin state $(S=5 / 2)$, obeying the Hund's rule. This calculated $\mathrm{Fe}^{2+}$ to $\mathrm{Fe}^{3+}$ transformation agrees with the in situ XANES measurements during charging in Fig. $3 \mathrm{~b}$. Moreover, the high structural stability of $\mathrm{KFeC}_{2} \mathrm{O}_{4} \mathrm{~F}$ upon charging/discharging under long cycles intimately associates with the above atomic and electronic properties. Figure $5 \mathrm{c}$ shows that the energy of $\mathrm{C}_{2} \mathrm{O}_{4}{ }^{2-}$ decomposition in the bulk $\mathrm{K}_{1-x} \mathrm{FeC}_{2} \mathrm{O}_{4} \mathrm{~F}$ continually decreases with the extraction of potassium ions over $x<0.875$, caused by the depletion of $\mathrm{Fe} 3 d$ electrons and the accumulation of $\mathrm{C} 2 p$ electrons near the $E_{\mathrm{F}}$ that are responsible for the redox reaction upon charging (Fig. $5 \mathrm{~d}$ ). At $x \geq 0.875$, it reveals a turning point to prevent the decomposition energy becoming too negative upon full $\mathrm{K}$ extraction, owing to the stable $3 d$ electron configuration with half-filled $t_{2 \mathrm{~g}}$ and $e_{\mathrm{g}}$ orbitals in $\mathrm{FeC}_{2} \mathrm{O}_{4} \mathrm{~F}$ according to the Hund's rule. Although the reaction energy indicates thermodynamically possible decomposition of $\mathrm{C}_{2} \mathrm{O}_{4}{ }^{2-}$ in the $\mathrm{K}_{1-\mathrm{x}} \mathrm{FeC}_{2} \mathrm{O}_{4} \mathrm{~F}$ during deep charge, its kinetic barrier of $\sim 1.4 \mathrm{eV}$ shown in Fig. 5e effectively inhibits the structure decomposition under ambient condition, resulting in a stable $3 \mathrm{D}$ framework for potassium battery chemistry.

Electrochemical performance of a full cell. In practical applications, owing to the high combustibility of metallic $\mathrm{K}$, a metallic
$\mathrm{K}$ battery would not be safe. Following this consideration, a prototype $\mathrm{K}$ ion full cell was configured by combining $\mathrm{KFeC}_{2} \mathrm{O}_{4} \mathrm{~F}$ cathode with a soft carbon (SC) anode. The working mechanism of the full cell is sketched in Fig. 6a, where $\mathrm{K}$ ions are removed from $\mathrm{KFeC}_{2} \mathrm{O}_{4} \mathrm{~F}$ and migrate into the $\mathrm{SC}$ anode during charging, and a reverse transformation occurs during discharging. Figure $6 \mathrm{~b}$ demonstrates that one prepared $\mathrm{K}$ ion full cell could power a LED screen. The rate performance of the full cell is shown in Fig. 6c, reaching a reversible capacity of 83.7, 71.0, 65.7 64.7, 62.6 $\mathrm{mAh} \mathrm{g}-1$ at a current rate from 0.1 to $0.5 \mathrm{~A} \mathrm{~g}^{-1}$. The discharge capacity returned back to $76.1 \mathrm{mAh} \mathrm{g}^{-1}$ when the current density recovered to $0.1 \mathrm{Ag}^{-1}$, demonstrating its good rate capability. Moreover, the full cell delivered a reversible capacity of $\sim 85 \mathrm{mAh}$ $\mathrm{g}^{-1}$ (based on the mass of the cathode) and remained stable with negligible capacity decay within 200 cycles at a current density of $0.1 \mathrm{Ag}^{-1}$ (Fig. 6d). The energy density of the full cell was estimated $\sim 235 \mathrm{Wh} \mathrm{kg}^{-1}$. The GCD curves at 200th, 100th, 50th, and 10th cycles almost overlap with each other (Fig. 6e), manifesting the considerable cycling stability of our full battery.

\section{Discussion}

In conclusion, we have identified $\mathrm{KFeC}_{2} \mathrm{O}_{4} \mathrm{~F}$ as a promising cathode candidate for KIBs. Owing to its intrinsic $\mathrm{Fe}^{2+} / \mathrm{Fe}^{3+}$ redox mechanism, rigid $3 \mathrm{D}\left[\mathrm{FeC}_{2} \mathrm{O}_{4} \mathrm{~F}\right]$ framework and three open channels, the $\mathrm{KFeC}_{2} \mathrm{O}_{4} \mathrm{~F}$ cathode yielded a reversible discharge capacity of $\sim 112 \mathrm{mAh} \mathrm{g}^{-1}$ at $0.2 \mathrm{~A} \mathrm{~g}^{-1}$ and kept high capacity retention of $94 \%$ over 2000 cycles, with $0.003 \%$ capacity fading per cycle. Moreover, a full $\mathrm{K}$ ion cell was successfully constructed by combining this $\mathrm{KFeC}_{2} \mathrm{O}_{4} \mathrm{~F}$ cathode with soft carbon anode, which delivered negligible capacity decay for 200 cycles with 
a
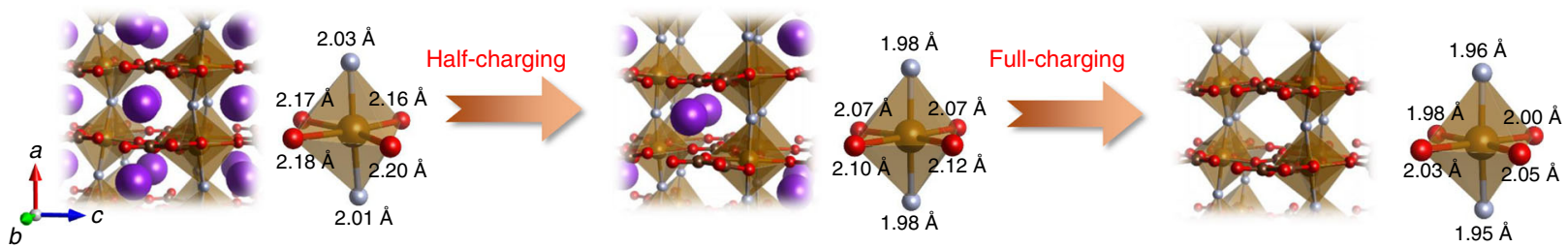

b
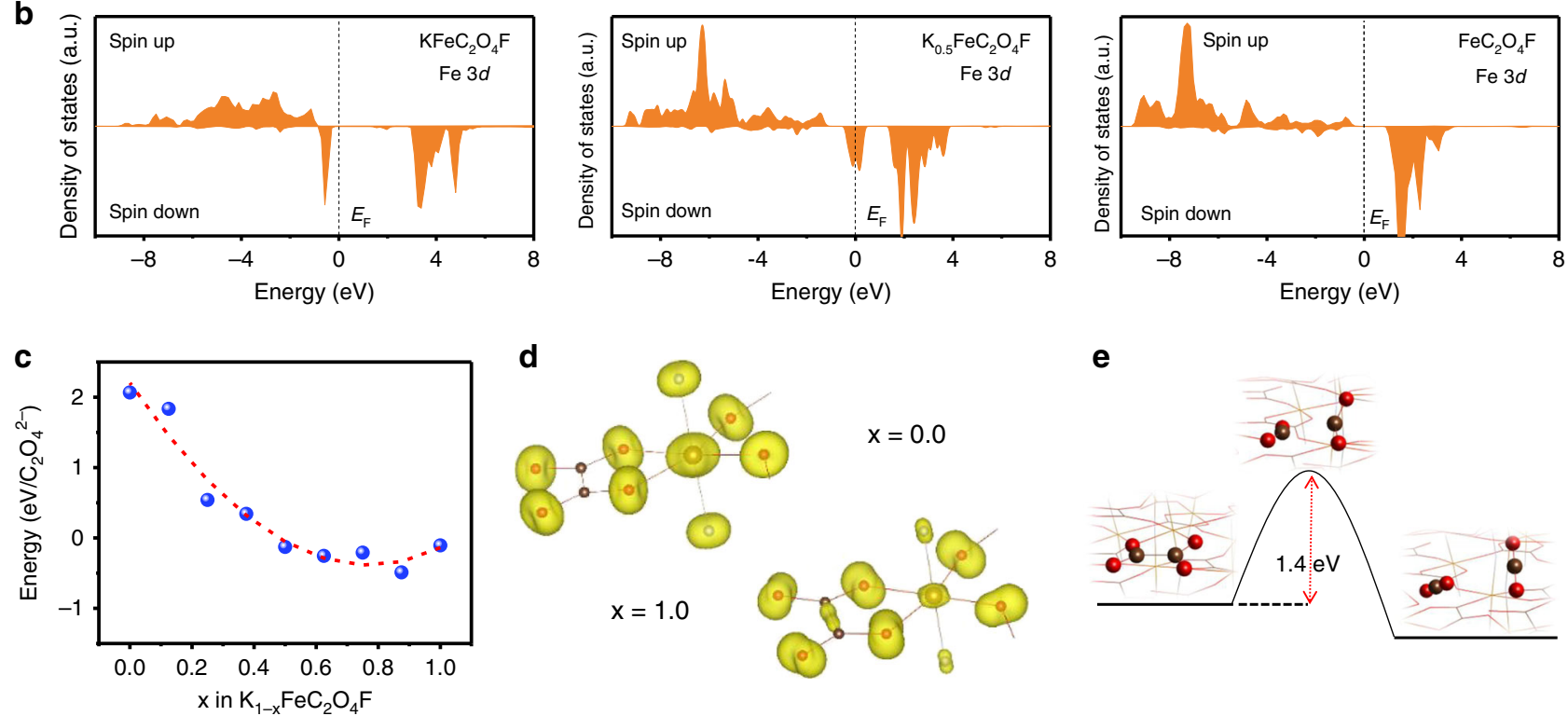

e

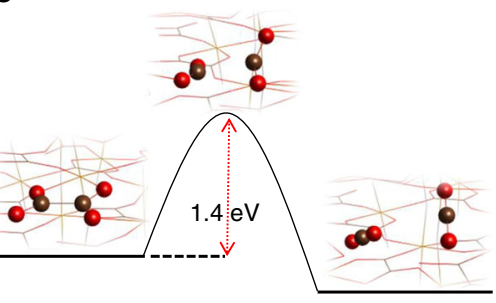

Fig. 5 First-principles calculations. a Calculated atomic structures of $\mathrm{K}_{1-x} \mathrm{FeC}_{2} \mathrm{O}_{4} \mathrm{~F}$ in the pristine, half-charging and full-charging states $(x=0,0.5,1)$, and $\mathbf{b}$ their corresponding partial density of states (DOS) projected onto the $\mathrm{Fe} 3 d$ orbitals. $\mathbf{c}$ The reaction energy of a $\mathrm{C}_{2} \mathrm{O}_{4}{ }^{2-}$ decomposing into $2 \mathrm{CO}_{2}$ in the bulk of $\mathrm{K}_{1-x} \mathrm{FeC}_{2} \mathrm{O}_{4} \mathrm{~F}$ as a function of the charge state $x$. $\mathbf{d}$ The partial charge density for electrons in the energy range between $-2.5 \mathrm{eV}$ and the Fermi level $(\mathrm{OeV})$ of the pristine $(x=0)$ and full-charging $(x=1)$ states. e The reaction scheme and kinetics of a $\mathrm{C}_{2} \mathrm{O}_{4}{ }^{2-}$ decomposing into $2 \mathrm{CO}_{2}$ in the bulk of $\mathrm{K}_{0.125} \mathrm{FeC}_{2} \mathrm{O}_{4} \mathrm{~F}$. Based on the Brønsted-Evans-Polanyi relation, the reaction barrier is linearly related to the reaction energy. Therefore, the reaction barrier in $\mathrm{K}_{0.125} \mathrm{FeC}_{2} \mathrm{O}_{4} \mathrm{~F}$ with the lowest decomposition energy represents the minimum barrier in $\mathrm{K}_{1-x} \mathrm{FeC}_{2} \mathrm{O}_{4} \mathrm{~F}$.

a

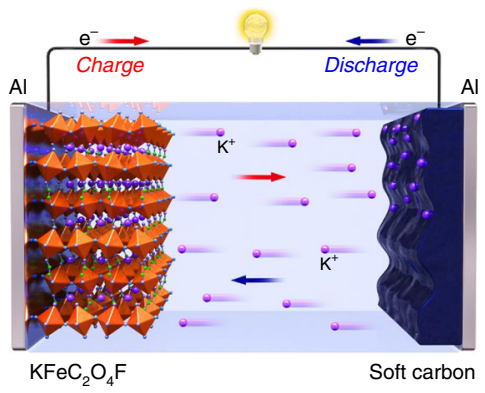

d

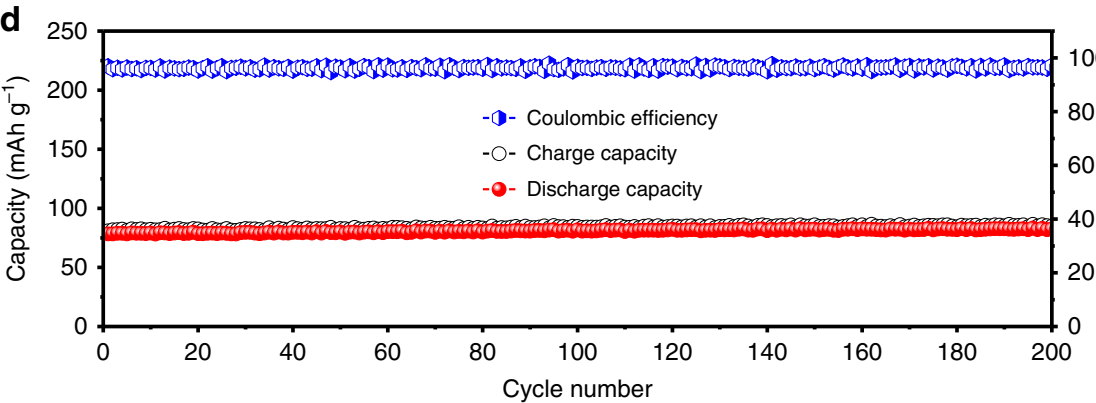

b

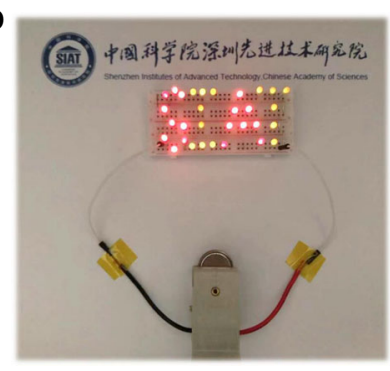

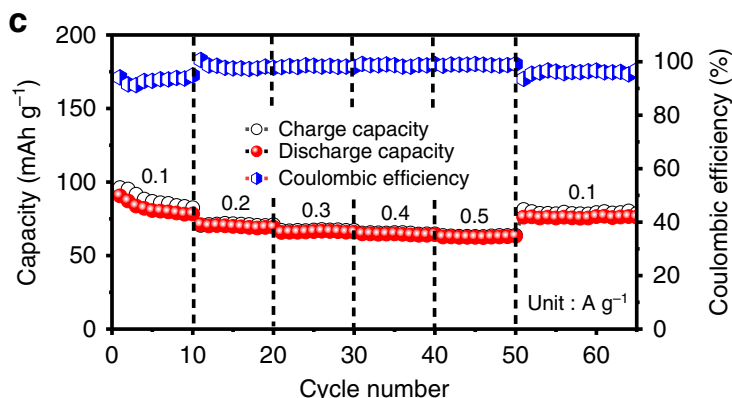

Fig. 6 Electrochemical measurements of full $\mathbf{K}$ ion cell in 1.7-4.4 V. a Schematic illustration of working mechanism. b Lit LED screen driven by a K ion full cell. c Charge-discharge capacities and corresponding coulombic efficiency of a full cell under different current densities. $\mathbf{d}$ Cycling performance of a full cell at $0.1 \mathrm{~A} \mathrm{~g}^{-1}$, and $\mathbf{e}$ the corresponding charge-discharge curves of different cycles. 
energy density of $\sim 235 \mathrm{Wh} \mathrm{kg}^{-1}$ and impressive rate performance. Although the performance of this $\mathrm{K}$ ion full cell may be further enhanced by optimizing the electrolyte systems and utilizing suitable anode materials, etc., this study clearly indicates the feasibility of $\mathrm{KFeC}_{2} \mathrm{O}_{4} \mathrm{~F}$ as a promising $\mathrm{KIB}$ cathode for sustainable large-scale energy storage applications.

\section{Methods}

Materials. Iron (II) oxalate dihydrate $\left(\mathrm{FeC}_{2} \mathrm{O}_{4} \cdot 2 \mathrm{H}_{2} \mathrm{O}, 99.5 \%\right)$, oxalic acid dihydrate $\left(\mathrm{H}_{2} \mathrm{C}_{2} \mathrm{O}_{4} \cdot 2 \mathrm{H}_{2} \mathrm{O}, 99.8 \%\right)$, potassium fluoroborate $\left(\mathrm{KBF}_{4}, 99.99 \%\right)$, potassium carbonate $\left(\mathrm{K}_{2} \mathrm{CO}_{3}, 99 \%\right)$, perylene-3,4,9,10-tetracarboxylic dianhydride (PTCDA), and potassium block (K, 99\%) were purchased from Aladdin Reagent. Polyvinylidene fluoride (PVDF) binder, and $N$-methyl-2-pyrrolidone (NMP) were provided by Shenzhen KejingStar Technology. Ketjenblack EC600JD was purchased from Lion Corporation in Japan. Potassium hexafluorophosphate $\left(\mathrm{KPF}_{6}\right.$, 99.99\%), propylene carbonate (PC, 99.95\%), ethylene carbonate (EC, 99.95\%), and potassium molecular sieve were provided by Dodochem. The glass fiber separator (Whatman, $47 \mathrm{~mm}$ ) was bought from Shanghai Huanao Technology Ltd. All of the above were used directly as received without further self-processing.

Sample preparation. Single crystals of $\mathrm{KFeC}_{2} \mathrm{O}_{4} \mathrm{~F}$ were grown via a hydrothermal reaction in mild conditions. A mixture of $\mathrm{FeC}_{2} \mathrm{O}_{4} \cdot 2 \mathrm{H}_{2} \mathrm{O}, \mathrm{H}_{2} \mathrm{C}_{2} \mathrm{O}_{4} \cdot 2 \mathrm{H}_{2} \mathrm{O}, \mathrm{KBF}_{4}$, and $\mathrm{K}_{2} \mathrm{CO}_{3}$ in the molar ratio of 1:3:2:4 (one for $1 \mathrm{mmol}$ ) was put in a Teflon-lined autoclave with $1 \mathrm{~mL}$ distilled water. After sealing, the autoclave was moved to a $180^{\circ} \mathrm{C}$ oven for $48 \mathrm{~h}$, then cooled to room temperature by turning off the oven. The resulting product was filtered with distilled water for several times until all byproducts being removed, and then dried at a vacuum environment overnight. The soft carbon was fabricated facilely by thermal polymerizing PTCDA at a heating rate of $10^{\circ} \mathrm{C} \mathrm{min}^{-1}$ until $900^{\circ} \mathrm{C}$ and kept for $4 \mathrm{~h}$.

Characterization. The optical images of as-synthesized crystallites were taken by a Leica DVM6M video microscope with ultra-depth-of-field. For the transmission electron microscope (TEM) characterization, a single crystallite was directly moved to the focused ion beam (FIB) chamber. A sheet section from the crystallite was prepared by a FEI Scios FIB/FE-SEM at an accelerating voltage of $30 \mathrm{kV}$ under a selective etching process. The final sheet of the sample was positioned and secured on a $\mathrm{Cu}$ grid and transferred to the TEM chamber. The EDS of TEM were conducted by a JEOL JEM-3200FS field emission TEM equipped with an Oxford Instruments EDS analyzer. SEM measurements and EDS element mapping of the sample were carried out on ZEISS SUPRA 55 equipped with an EDS analyzer.

Powder XRD patterns were collected by a Rigaku diffractometer (MiniFlex600) with $\mathrm{Cu} K \alpha$ radiation $(\lambda=0.154056 \mathrm{~nm})$. Scans were taken with a $2 \theta$ step of $0.02^{\circ}$ over the range of $10-80^{\circ}$. Rietveld method was used to refine the data sets using the GSAS package incorporated with the EXPGUI interface ${ }^{60}$. Parameters, such as scale factor, background, lattice parameters, and zero point were refined until convergence. Analyses of recollected cathodes at different states, after being washed with PC to remove electrolyte and dried overnight, were conducted on the same $\mathrm{XRD}$ detector at a $2 \theta$ step of $2^{\circ} \mathrm{min}^{-1}$ over the range of $10-60^{\circ}$. Variabletemperature XRD patterns were recorded on a Smartlab $9 \mathrm{KW}$ diffractometer equipped with a SmartLab SOH-150F furnace with $\mathrm{Cu} K \alpha$ radiation. The scans were performed in the $2 \theta$ step of $2^{\circ} \mathrm{min}^{-1}$ in the range of $10-60^{\circ}$ when heating samples from room temperature to $310^{\circ} \mathrm{C}$ at various intervals.

The thermal behavior of $\mathrm{KFeC}_{2} \mathrm{O}_{4} \mathrm{~F}$ was detected by simultaneous thermogravimetric and differential scanning calorimetry using a STA449F3 thermal analyzer (Netzsch, Germany). Hand-ground crystallites of $\sim 10 \mathrm{mg}$ were placed in an alumina crucible and heated from room temperature to $800^{\circ} \mathrm{C}$ under a flow of air at a rate of $10^{\circ} \mathrm{C} \mathrm{min}-1$. Fourier transform infrared (FTIR) spectrum was collected by a Perkin Elmer Frontier FTIR spectrometer in the range $400-4000 \mathrm{~cm}^{-1}$ with a resolution of $1 \mathrm{~cm}^{-1}$. The Raman spectrum was carried out using HORIBA, XploRA PLUS detector in the backscattering mode at the frequency range of $400-2000 \mathrm{~cm}^{-1}$. The wavelength resolution and probe aperture are $1 \mathrm{~cm}^{-1}$ and near $10 \mu \mathrm{m}$, respectively.

Electrochemical characterization. The electrochemical performance of $\mathrm{KFeC}_{2} \mathrm{O}_{4} \mathrm{~F}$ was studied in CR2032 coin-type half-cells assembled in an glove box (MIKROUNA) filled with high pure Argon gas, with water and oxygen levels $<0.1 \mathrm{ppm}$. $\mathrm{KFeC}_{2} \mathrm{O}_{4} \mathrm{~F}$ crystallites were first hand-milled for several minutes and then ball milled for $4 \mathrm{~h}$ using a high-energy planetary ball mill. To improve the conductivity of $\mathrm{KFeC}_{2} \mathrm{O}_{4} \mathrm{~F}$, the above-mentioned sample was ball milled again with Kejten black carbon $(3: 1 \mathrm{w} / \mathrm{w})$ for $8 \mathrm{~h}$. Samples at each states were checked under powder XRD, ensuring the sample was not contaminated or destroyed during milling (Supplementary Figs. 3, 4). The subsequent powder was mixed with PVDF (85\%:15\% w/w), and NMP was added drop-by-drop until forming a homogeneous slurry. The slurry was then hand coated onto a carbon-coated $\mathrm{Al}$ foil, and dried at $80^{\circ} \mathrm{C}$ in vacuum for $12 \mathrm{~h}$ and punched into circular sheets with diameters of $10 \mathrm{~mm}$ and loading mass of $\sim 1.0 \mathrm{mg} \mathrm{cm}^{-2}$. Potassium metal foils, $1 \mathrm{M} \mathrm{KPF}_{6}$ in $\mathrm{EC}: \mathrm{PC}=1: 1(\mathrm{v} / \mathrm{v})$ and glass fiber sheets (16 mm in diameter) were used as counter electrode, electrolyte and separators, respectively. Galvanostatic charge-discharge and galvanostatic intermittent titration technique (GITT) tests were performed on a battery test system (NEWARE CT-4008). Before GITT measurements, cells were initially activated for several cycles at $0.1 \mathrm{~A} \mathrm{~g}^{-1}$, and subsequently charged or discharged for $10 \mathrm{~min}$ at a pulse current of $50 \mathrm{~mA} \mathrm{~g}^{-1}$, followed by a duration of $10 \mathrm{~min}$ relaxation to achieve potassium equilibrium potential. Cyclic voltammetry and electrochemical impedance spectroscopy were performed on an Autolab (PGSTAT302N, Switzerland) electrochemical workstation. The full battery was assembled in similar conditions as half-cells, except that the anode was replaced by SC.

Synchrotron-based X-ray tests were performed on CR2016 coin-type half-cells with two sides kapton windows at SUT-NANOTEC-SLRI XAS beamline (BL5.2), Synchrotron Light Research Institute (SLRI, public organization), Thailand. ${ }^{61} \mathrm{~A}$ beam energy of $1.2 \mathrm{GeV}$ generates the synchrotron radiation source at the storage ring and the beamline photon source covers an energy range of $40-1040 \mathrm{eV}$ at the resolving power of 10,000 . The typical loading of $\mathrm{KFeC}_{2} \mathrm{O}_{4} \mathrm{~F}$ cathode is $5-8 \mathrm{mg} \mathrm{cm}^{-2}$.

Calculations. All calculations presented were performed by the Vienna ab initio simulation package based on spin-polarized $\mathrm{DFT}^{62,63}$, with projector-augmentedwave method ${ }^{64,65}$ and a plan-wave cutoff energy of $450 \mathrm{eV}$. The Perdew-Burke-Ernzerhof functional ${ }^{66}$ with the Hubbard U correction ${ }^{67}$ was adopted for the exchange correlation energy. A value of $4.0 \mathrm{eV}$ was applied to $\mathrm{U}$ to correct the onsite Coulomb repulsion of Fe $3 d$ electrons ${ }^{68}$. The Brillouin zone was sampled with a $6 \times 4 \times 4 \Gamma$-centered $\mathrm{k}$ mesh to keep the reciprocal spacing of all calculations with supercells of $\mathrm{K}_{8-x} \mathrm{Fe}_{8}\left(\mathrm{C}_{2} \mathrm{O}_{4}\right)_{8} \mathrm{~F}_{8}(8 \geq x \geq 0)<0.03 \AA^{-1}$. The criteria for energy convergence was set to be $10^{-5} \mathrm{eV}$. The optimized orthorhombic lattice of $\mathrm{K}_{8} \mathrm{Fe}_{8}\left(\mathrm{C}_{2} \mathrm{O}_{4}\right)_{8} \mathrm{~F}_{8}$ is $7.81 \times 11.92 \times 10.48 \AA$, consistent well with the lattice determined by XRD as $7.76 \times 11.86 \times 10.40 \AA$. The oxalate dissociation barriers in the bulk were simulated using climbing image nudged elastic band method ${ }^{69}$ with force convergence criteria on each atom of $0.05 \mathrm{eV}^{-1}$.

\section{Data availability}

The data that support the plots within this paper and other findings of this study are available from the corresponding author upon reasonable request.

Received: 18 October 2019; Accepted: 18 February 2020;

Published online: 06 March 2020

\section{References}

1. Tarascon, J.-M. \& Armand, M. Issues and challenges facing rechargeable lithium batteries. Nature 414, 359-367 (2001).

2. Li, M., Lu, J., Chen, Z. \& Amine, K. 30 years of lithium-ion batteries. $A d v$ Mater. 30, 1800561 (2018).

3. Goodenough, J. B. \& Park, K. S. The Li-ion rechargeable battery: a perspective J. Am. Chem. Soc. 135, 1167-1176 (2013).

4. Dunn, B., Kamath, H. \& Tarascon, J. M. Electrical energy storage for the grid: a battery of choices. Science 334, 928-935 (2011).

5. Goodenough, J. B. \& Kim, Y. Challenges for rechargeable Li batteries. Chem. Mater. 22, 587-603 (2010).

6. Lu, J., Wu, T. \& Amine, K. State-of-the-art characterization techniques for advanced lithium-ion batteries. Nat. Energy 2, 1-13 (2017).

7. Larcher, D. \& Tarascon, J. M. Towards greener and more sustainable batteries for electrical energy storage. Nat. Chem. 7, 19-29 (2015).

8. Han, M. H., Gonzalo, E., Singh, G. \& Rojo, T. A comprehensive review of sodium layered oxides: powerful cathodes for Na-ion batteries. Energy Environ. Sci. 8, 81-102 (2015)

9. Jiang, C. et al. A multi-ion strategy towards rechargeable sodium-ion full batterieswith high working voltage and rate capability. Angew. Chem. Int. Ed. 57, 16370-16374 (2018).

10. Kim, S.-W., Seo, D.-H., Ma, X., Ceder, G. \& Kang, K. Electrode materials for rechargeable sodium-ion batteries: potential alternatives to current lithiumion batteries. Adv. Energy Mater. 2, 710-721 (2012).

11. Xie, D., Zhang, M., Wu, Y., Xiang, L. \& Tang, Y. A flexible dual-ion battery based on sodium-ion quasi-solid-state electrolyte with long cycling life. Adv. Funct. Mater. 30, 1906770 (2020).

12. Kundu, D., Talaie, E., Duffort, V. \& Nazar, L. F. The emerging chemistry of sodium ion batteries for electrochemical energy storage. Angew. Chem. Int. Ed. 54, 3431-3448 (2015).

13. Zhang, W., Liu, Y. \& Guo, Z. Approaching high-performance potassium-ion batteries via advanced design strategies and engineering. Sci. Adv. 5, eaav7412 (2019).

14. $\mathrm{Xu}, \mathrm{Y}$. et al. Enhancing potassium-ion battery performance by defect and interlayer engineering. Nanoscale Horiz. 4, 202-207 (2019). 
15. Hwang, J.-Y., Myung, S.-T. \& Sun, Y.-K. Recent progress in rechargeable potassium. Batteries. Adv. Func. Mater. 28, 1802938 (2018).

16. Ji, B., Zhang, F., Wu, N. \& Tang, Y. A dual-carbon battery based on potassium-ion electrolyte. Adv. Energy Mater. 7, 1700920 (2017).

17. Marcus, Y. International union of pure and applied chemistry. Pure Appl. Chem. 57, 1129-1132 (1985)

18. Okoshi, M., Yamada, Y., Komaba, S., Yamada, A. \& Nakai., H. Theoretical analysis of interactions between potassium ions and organic electrolyte solvents: a comparison with lithium, sodium, and magnesium ions. J. Electrochem. Soc. 164, A54-A60 (2017).

19. Lei, K. et al. High K-storage performance based on the synergy of dipotassium terephthalate and ether-based electrolytes. Energy Environ. Sci. 10, 552-557 (2017).

20. Chang, X. et al. Ultrahigh nitrogen doping of carbon nanosheets for high capacity and long cycling potassium ion storage. Adv. Energy Mater. 9, 1902672 (2019).

21. Nobuhara, K., Nakayama, H., Nose, M., Nakanishi, S. \& Iba, H. Firstprinciples study of alkali metal-graphite intercalation compounds. J. Power Sources 243, 585-587 (2013).

22. Komaba, S., Hasegawa, T., Dahbi, M. \& Kubota, K. Potassium intercalation into graphite to realize high-voltage/high-power potassium-ion batteries and potassium-ion capacitors. Electrochem. Commun. 60, 172-175 (2015).

23. Jian, Z., Luo, W. \& Ji, X. Carbon electrodes for K-ion batteries. J. Am. Chem. Soc. 137, 11566-11569 (2015).

24. Xu, Y. et al. Highly nitrogen doped carbon nanofibers with superior rate capability and cyclability for potassium ion batteries. Nat. Commun. 9, 1720 (2018).

25. Shannon, R. D. Revised effective ionic radii and systematic studies of interatomie distances in halides and chaleogenides. Acta Cryst. A32, 751-767 (1976).

26. Kim, H. et al. K-Ion Batteries Based on a P2-Type $\mathrm{K}_{0.6} \mathrm{CoO}_{2}$ Cathode. $A d v$. Energy Mater. 7, 1700098 (2017)

27. Hwang, J.-Y., Kim, J., Yu, T.-Y., Myung, S.-T. \& Sun, Y.-K. Development of P3- $\mathrm{K}_{0.69} \mathrm{CrO}_{2}$ as an ultra-high-performance cathode material for K-ion batteries. Energy Environ. Sci. 11, 2821-2827 (2018).

28. Masese, T. et al. Rechargeable potassium-ion batteries with honeycomblayered tellurates as high voltage cathodes and fast potassium-ion conductors. Nat. Commun. 9, 3823 (2018).

29. Kim, $\mathrm{H}$. et al. Investigation of potassium storage in layered P3-Type $\mathrm{K}_{0.5} \mathrm{MnO}_{2}$ cathode. Adv. Mater. 29, 1702480 (2017).

30. Gao, A. et al. K-brnessite electrode obtained by ion exchange for potassiumion batteries: insight into the concerted ionic diffusion and $\mathrm{K}$ storage mechanism. Adv. Energy Mater. 9, 1802739 (2019).

31. Zhu, Y. H. et al. Transformation of rusty stainless-steel meshes into stable, low-cost, and binder-free cathodes for high-performance potassium-ion batteries. Angew. Chem. Int. Ed. 56, 7881-7885 (2017).

32. Zhang, C. et al. Potassium prussian blue nanoparticles: a low-cost cathode material for potassium-ion batteries. Adv. Funct. Mater. 27, 1604307 (2017).

33. Xue, L. et al. Low-cost high-energy potassium cathode. J. Am. Chem. Soc. 139, 2164-2167 (2017).

34. Wang, J. et al. A bi-functional device for self-powered electrochromic window and self-rechargeable transparent battery applications. Nat. Commun. 5, 4921 (2014).

35. Pei, Y., Mu, C., Li, H., Li, F. \& Chen, J. Low-cost $\mathrm{K}_{4} \mathrm{Fe}(\mathrm{CN})_{6}$ as a highvoltage cathode for potassium-ion batteries. Chem. Sus. Chem. 11, 1285-1289 (2018).

36. Chen, Y. et al. Organic electrode for non-aqueous potassium-ion batteries. Nano Energy 18, 205-211 (2015).

37. Fan, L., Ma, R., Wang, J., Yang, H. \& Lu, B. An ultrafast and highly stable potassium-organic battery. Adv. Mater. 30, 1805486 (2018).

38. Han, J. et al. Nanocubic $\mathrm{KTi}_{2}\left(\mathrm{PO}_{4}\right)_{3}$ electrodes for potassium-ion batteries. Chem. Commun. 52, 11661-11664 (2016).

39. Gao, H., Xue, L., Xin, S. \& Goodenough, J. B. A high-energy-density potassium battery with a polymer-gel electrolyte and a polyaniline cathode. Angew. Chem. Int. Ed. 57, 5449-5453 (2018).

40. Ding, Y. et al. A liquid-metal-enabled versatile organic alkali-ion battery. $A d v$. Mater. 31, 1806956 (2019).

41. Park, W. B. et al. $\mathrm{KVP}_{2} \mathrm{O}_{7}$ as a robust high-energy cathode for potassium-ion batteries: pinpointed by a full screening of the inorganic registry under specific search conditions. Adv. Energy Mater. 8, 1703099 (2018).

42. Kim, H. et al. A new strategy for high-voltage cathodes for K-ion batteries: stoichiometric $\mathrm{KVPO}_{4}$ F. Adv. Energy Mater. 8, 1801591 (2018).

43. Lin, B. et al. Birnessite nanosheet arrays with high $\mathrm{K}$ content as a highcapacity and ultrastable cathode for K-ion batteries. Adv. Mater. 31, 1900060 (2019).

44. Lin, X., Huang, J., Tan, H., Huang, J. \& Zhang, B. $\mathrm{K}_{3} \mathrm{~V}_{2}\left(\mathrm{PO}_{4}\right)_{2} \mathrm{~F}_{3}$ as a robust cathode for potassium-ion batteries. Energy Storage Mater. 16, 97-101 (2019).
45. $\mathrm{Lu}, \mathrm{K}$. et al. Rechargeable potassium-ion batteries enabled by potassiumiodine conversion chemistry. Energy Storage Mater. 16, 1-5 (2019).

46. Zhang, L. et al. Constructing the best symmetric full K-ion battery with the NASICON-type $\mathrm{K}_{3} \mathrm{~V}_{2}\left(\mathrm{PO}_{4}\right)_{3}$. Nano Energy 60, 432-439 (2019).

47. Choi, J. U. et al. $\mathrm{K}_{0.54}\left[\mathrm{Co}_{0.5} \mathrm{Mn}_{0.5}\right] \mathrm{O}_{2}$ : new cathode with high power capability for potassium-ion batteries. Nano Energy 61, 284-294 (2019).

48. Hosaka, T., Shimamura, T., Kubota, K. \& Komaba, S. Polyanionic compounds for potassium-ion batteries. Chem. Rec. 18, 1-12 (2018).

49. Xu, Y.-S. et al. Recent developments in electrode materials for potassium-ion batteries. J. Mater. Chem. A 7, 4334-4352 (2019).

50. He, G. \& Nazar, L. F. Crystallite size control of prussian white analogues for nonaqueous potassium-ion batteries. ACS Energy Lett. 2, 1122-1127 (2017).

51. Tustain, K. et al. Materialization of a geometrically frustrated magnet in a hybrid coordination framework: a study of the iron(II) oxalate fluoride framework, $\mathrm{KFe}\left(\mathrm{C}_{2} \mathrm{O}_{4}\right) \mathrm{F}$. Inorg. Chem. 58, 11971-11977 (2019).

52. Yao, W. et al. Diverse family of layered frustrated magnets with tailorable interlayer interactions. Chem. Mater. 29, 6616-6620 (2017).

53. Frost, R. L., Locke, A. \& Martens, W. N. Synthesis and Raman spectroscopic characterisation of the oxalate mineral wheatleyite $\mathrm{Na}_{2} \mathrm{Cu}^{2+}\left(\mathrm{C}_{2} \mathrm{O}_{4}\right)_{2} \cdot 2 \mathrm{H}_{2} \mathrm{O}$. J. Raman Spectrosc. 39, 901-908 (2008)

54. Recham, N. et al. A 3.6 V lithium-based fluorosulphate insertion positive electrode for lithium-ion batteries. Nat. Mater. 9, 68-74 (2010).

55. Turner, S. O. et al. Direct imaging of loaded metal-organic framework materials (Metal@MOF-5). Chem. Mater. 20, 5622-5627 (2008).

56. Houk, R. J. et al. Silver cluster formation, dynamics, and chemistry in metal-organic frameworks. Nano Lett. 6, 3413-3418 (2009).

57. Song, T. et al. A low-cost and environmentally friendly mixed polyanionic cathode for sodium-ion storage. Angew. Chem. Int. Ed. 59, 740-745 (2020).

58. Park, M., Zhang, X., Chung, M., Less, G. B. \& Sastry, A. M. A review of conduction phenomena in Li-ion batteries. J. Power Sources 195, 7904-7929 (2010).

59. Ouyang, C. Y., Shi, S. Q., Fang, Q. \& Lei, M. S. $\mathrm{Li}_{1+\mathrm{x}} \mathrm{FePO}_{4}(0 \leq \mathrm{x} \leq 3)$ as anode material for lithium ion batteries: from ab initio studies. J. Power Sources $\mathbf{1 7 5}$, 891-896 (2008).

60. Toby, B. H. EXPGUI, a graphical user interface for GSAS. J. Appl. Cryst. 34, 210-213 (2001)

61. Yao, W. et al. An oxalate cathode for lithium ion batteries with combined cationic and polyanionic redox. Nat. Commun. 10, 3483 (2019).

62. Kresse, G. \& Hafner, J. Ab initio molecular dynamics for liquid metals. Phys Rev. B 47, 558-561 (1993).

63. Kresse, G. \& Hafner, J. Ab initio molecular-dynamics simulation of the liquidmetal-amorphous-semiconductor transition in germanium. Phys. Rev. B 49, 14251-14269 (1994)

64. Blöchl, P. E. Projector augmented-wave method. Phys. Rev. B 50, 17953-17979 (1994).

65. Kresse, G. \& Joubert, D. From ultrasoft pseudopotentials to the projector augmented-wave method. Phys. Rev. B 59, 1758-1775 (1999).

66. John, P. P., Kieron., B. \& Matthias, E. Generalized gradient approximation made simple. Phys. Rev. Lett. 77, 3865-3868 (1996).

67. Dudarev, S. L., Botton, G. A., Savrasov, S. Y., Humphreys, C. J. \& Sutton, A. P. Electron-energy-loss spectra and the structural stability of nickel oxide: an LSDA+U study. Phys. Rev. B 57, 1505-1509 (1998).

68. Wang, L., Maxisch, T. \& Ceder, G. Oxidation energies of transition metal oxides within the GGA+U framework. Phys. Rev. B 73, 195107 (2006).

69. Henkelman, G., Uberuaga, B. P. \& Jónsson, H. A climbing image nudged elastic band method for finding saddle points and minimum energy paths. $J$. Chem. Phys. 113, 9901-9904 (2000).

\section{Acknowledgements}

We acknowledge the financial support from the National Natural Science Foundation of China (51822210, 51902339, 51972329), SIAT Innovation Program for Excellent Young Researchers (201811, 201825), the Science and Technology Planning Project of Guangdong Province (2018A050506066, 2019B090914003), Shenzhen Science and Technology Planning Project (JCYJ20170818153427106, JCYJ20180507182512042), and the Program for Guangdong Innovative and Entrepreneurial Teams (no. 2017ZT07C341).

\section{Author contributions}

The project was coordinated by Y.T.; Y.T. and H.C. conceived and designed the study; B.J., W.Y., and H.H. fabricated samples, performed the structural characterization and electrochemical experiments; Y.Z. conducted the simulation work; B.J. and X.Z. performed synchrotron-based and XRD characterizations; S.T., P.K., and S.S. analyzed data 
of synchrotron X-ray tests; B.J., W.Y., Y.Z., H.C., and Y.T. co-wrote the paper. All authors discussed the results and commented on the manuscript.

\section{Competing interests}

The authors declare no competing interests.

\section{Additional information}

Supplementary information is available for this paper at https://doi.org/10.1038/s41467020-15044-y.

Correspondence and requests for materials should be addressed to H.-M.C. or Y.T

Peer review information Nature Communications thanks Yong Lei and the other, anonymous, reviewer(s) for their contribution to the peer review of this work.

Reprints and permission information is available at http://www.nature.com/reprints
Publisher's note Springer Nature remains neutral with regard to jurisdictional claims in published maps and institutional affiliations.

(c) (i) Open Access This article is licensed under a Creative Commons Attribution 4.0 International License, which permits use, sharing, adaptation, distribution and reproduction in any medium or format, as long as you give appropriate credit to the original author(s) and the source, provide a link to the Creative Commons license, and indicate if changes were made. The images or other third party material in this article are included in the article's Creative Commons license, unless indicated otherwise in a credit line to the material. If material is not included in the article's Creative Commons license and your intended use is not permitted by statutory regulation or exceeds the permitted use, you will need to obtain permission directly from the copyright holder. To view a copy of this license, visit http://creativecommons.org/licenses/by/4.0/.

(c) The Author(s) 2020 